\title{
Comportamento do método quimioluminescente-ELISA em relação a resultados considerados discordantes por meio de três técnicas convencionais para diagnóstico da doença de Chagas
}

\author{
Behavior of the chemiluminescent ELISA method in relation to results considered \\ discordant via three conventional techniques for diagnosing Chagas disease
}

\author{
Cláudia Regina De Marchi ${ }^{1,2}$, Vicente Amato Neto ${ }^{1,2}$ e Igor Correia de Almeida ${ }^{3}$
}

\begin{abstract}
RESUMO
Quando utilizadas, em conjunto, a hemaglutinação indireta, a imunofluorescência indireta e ELISA para diagnóstico sorológico da doença de Chagas por vezes ocorrem resultados considerados discordantes, por não haver concordância entre o que indicam essas técnicas. A disponibilidade do método quimioluminescente-ELISA permitiu executá-lo com 200 soros que examinados pelos três testes citados que motivaram a obtenção de resultados discordantes. Com o método quimioluminescente-ELISA sucederam 193 negativos e sete positivos. O emprego desse novo procedimento trouxe mais um subsídio para compreensão do assunto, mas avanço mais concreto dependerá de documentação com soros de pessoas infectadas ou não pelo Trypanosoma cruzi conforme comprovação parasitológica.
\end{abstract}

Palavras-chaves: Doença de Chagas. Diagnóstico sorológico. Resultados duvidosos. Método quimioluminescente-ELISA.

\begin{abstract}
When indirect hemagglutination, indirect immunofhorescence and enzyme-linked immunosorbent assay are used together for serologically diagnosing Chagas disease, results that are considered discordant sometimes occur because there is disagreement between what these tests indicate. The availability of the chemiluminescent ELISA method enabled tests on 200 serum samples that had previously produced discordant results from the three abovementioned methods. CL-ELISA revealed that 193 of these samples were negative and seven were positive. The use of this new procedure provides further support for understanding this subject, but more concrete advances will depend on documentation with blood analyses from people previously demonstrated to be unquestionably infected or uninfected with Trypanosoma cruzi.
\end{abstract}

Key-words: Chagas disease. Serological diagnosis. Discordant results. Chemiluminescent ELISA.

Vários tipos de provas sorológicas são atualmente utilizados para possibilitar o diagnóstico da doença de Chagas. Constituem exames bastante efetuados para a identificação da parasitose em pessoas que estão na fase crônica da doença. Os testes mais em foco correspondem, no momento, à hemaglutinação indireta (HAI), à imunofluorescência indireta (IFI) e ao enzyme-linked immunosorbent assay (ELISA) ${ }^{45} 1214$. Nestes testes, conhecidos como convencionais, são usados habitualmente, como antígenos, extratos brutos de formas epimastigotas do Trypanosoma cruzi. A presença nessas preparações de inúmeros antígenos e epitopos, compartilhados com outros microorganismos, bem como a baixa diluição sorológica utilizada leva, freqüientemente, a resultados discordantes. Glicoinositolfosfolipídeos em seus terminais residuais de $\beta$-galactofuranose, ou presentes em glicoconjugados de fungos e Leishmania sp podem ser um dos responsáveis pela reatividade cruzada entre soros de pacientes com micoses ou leishmanioses e antígenos de T. cruzi.

Assim, os processos convencionais presentemente aplicados em hemoterapias ou mesmo de forma rotineira para diagnósticos têm apresentado resultados insatisfatórios em razão do grande número de amostras duvidosas ou falso-positivas.

\footnotetext{
1. Laboratório de Investigação Médica - Parasitologia do Hospital das Clínicas, Faculdade de Medicina, Universidade de São Paulo, São Paulo, SP. 2. Laboratório de Parasitologia Instituto de Medicina Tropical de São Paulo, Universidade de São Paulo, São Paulo, SP. 3. Departamento de Parasitologia, Instituto de Ciências Biomédicas, Universidade de São Paulo, São Paulo, SP.

Endereço para correspondência: Biomédica Cláudia Regina de Marchi. LIM/FM/USP. Av. Dr. Enéas de Carvalho Aguiar 500, 05403-000 São Paulo, SP, Brasil.

e-mail: claudiamarchi@yahoo.com.br

Recebido para publicação em 17/3/2006

Aceito em 17/1/2007
} 
Com o objetivo de solucionar esta situação, conceituados centros de pesquisas vêm empenhando-se no estudo de proteínas recombinates, peptídeos sintéticos e antígenos purificados 367891013 . Dentre os purificados imudominantes, em tarefas laboratoriais ocorre presentemente destaque para uma glicoproteína (glicosilfosfatidilinositol) ancorada do tipo mucina que quando isolada a partir de formas tripomastigotas do T. cruzi está propiciando altos índices de sensibilidade e especificidade $^{12}$.

Nesse contexto, ao lado dos expressivos benefícios que esses métodos proporcionam estão duas circunstâncias rememoráveis. Referimo-nos ao fato de ainda não contarmos com teste tido como gold standard, por atingir de forma cabal os objetivos almejados, ou seja, a apresentação de informações irrefutáveis, e também à ocorrência de resultados qualificados como indeterminados, por não haver concordância entre o que indicam as técnicas utilizadas. Esse contratempo tem implicações muito impróprias, pois se no grupo de três provas uma registra negatividade, fica simples deduzir que advirá grave erro quanto à interpretação. Por exemplo, isso é muitas vezes comprovado quando há análise de soros em conjunto, através de HI, IFI e ELISA, nas atividades rotineiras.

Como tentativa de propiciar novos conhecimentos quanto aos resultados discordantes executamos comparação entre verificações obtidas por três técnicas convencionais (HAI, IFI e ELISA) e a quimioluminescente-ELISA (CL-ELISA).

\section{MATERIAL E MÉTODOS}

Utilizamos 200 amostras glicerinadas (v/v) de soros humanos, mantidas a $4^{\circ} \mathrm{C}$, com as três provas sorológicas convencionais (HAI; IFI; ELISA) revelando resultados discordantes entre si, considerados os valores aceitos como significativos para doença de Chagas.

Quanto às técnicas adotadas, elas foram, para HI, IFI e ELISA, respectivamente as indicadas por Hoshino-Shimizu e cols $^{11}$, Camargo ${ }^{4}$ e Voller e cols ${ }^{14}$, convindo contudo registrar, em prosseguimento, alguns detalhes a respeito delas.

Hemaglutinação indireta. Foi realizada como descrita por Hoshino-Shimizu e cols ${ }^{11}$. Os reagentes utilizados foram comerciais (Cecon - Centro de Controle de Produtos para Diagnósticos Ltda) com hemácias de galinha ou ganso sensibilizadas com formas epimastigotas brutas de T. cruzi e soros diluídos a 1/20, 1/40, 1/80 e 1/160; 1/40 é comumente tido como aceitável para diagnóstico da doença de Chagas.

Imunofluorescência indireta. A IFI quantitativa (IgG) foi realizada nos títulos de 20, 40, 80 e 160 utilizando metodologia padronizada por Camargo ${ }^{4}$. Foi utilizado antígeno bruto de formas epimastigotas (Cecon - Centro de Controle de Produtos para Diagnósticos Ltda) para sensibilização das lâminas e conjugado (anti-imunoglobulinas) anti-IgG humano marcado com isotiocianato de fluoresceína (Biolab). 0 título 1/40 é comumente tido como aceitável para diagnóstico da doença de Chagas.

ELISA. Foi utilizado kit comercial Hemobio Chagas HBK 401 (Empresa Brasileira de Biotecnologia S.A. - Embrabil) com extrato bruto de formas epimastigotas, com soro na diluição 1:201. Leitura por densidade ótica em espectofotômetro, com filtro de leitura a 450nm, e de referência a 620nm em ELISA-LP 400 Microplate Reader. 0 limiar de reatividade (LR) foi encontrado através da media aritimédica de três controles negativos mais 0,300 (conforme instruções do kit). Azona cinza foi estabelecida somando-se e subtraindo-se $10 \%$ ao valor do LR.

CL-ELISA. Foi realizada conforme instruções de Almeida e cols ${ }^{4}$. A obtenção do antígeno partiu da purificação de mucinas de formas tripomastigotas do T. cruzi na concentração de 188pg/50 1 l em cada poço da placa, com soro a 1:1000. Inicialmente, para determinar o limiar de reatividade (LR) houve emprego de painel de 52 soros de pacientes com doença de Chagas, comprovada por hemocultura, e de 100 soros de indivíduos sem a parasitose, ficando estabelecido valor de corte de 0,729 . Para estabelecer a zona cinza houve soma e subtração de $10 \%$ dos valores de LR.

As formas tripomastigotas do T. cruzi, de cepa identificação como Y, foram obtidas a partir do sobrenadante do 5o ao $8^{\circ}$ dia da cultura de células LLCMK $_{2}$ (monkey kidney epithelial).

\section{RESULTADOS}

Das 200 amostras com resultados discordantes derivados de técnicas convencionais (HAI, IFI e ELISA), em 193 sucederam resultados negativos em CL-ELISA, efetuada com mucinas purificadas de tripomastigotas (Muc-TCT), e quanto a somente sete amostras houve positividade. Não encontramos amostras na zona cinza (Tabela 1).

Tabela 1 - Resultados de exames para diagnóstico da doença de Chagas considerados discordantes por meio de três técnicas convencionais, comparados com os decorrentes do método da quimioluminescente-ELISA.

\begin{tabular}{lrrrrrr}
\hline \multirow{2}{*}{ Técnicas } & \multicolumn{2}{c}{ Discordantes } & \multicolumn{2}{c}{ Positivos } & \multicolumn{2}{c}{ Negativos } \\
\cline { 2 - 7 } & \multicolumn{1}{c}{$\mathrm{n}^{\underline{0}}$} & \multicolumn{1}{c}{$\%$} & $\mathrm{n}^{\underline{0}}$ & $\%$ & $\mathrm{n}^{0}$ & $\%$ \\
\hline $\mathrm{HI}$ & 200 & 100,0 & 0 & 0,0 & 0 & 0,0 \\
$\mathrm{IFI}$ & 200 & 100,0 & 0 & 0,0 & 0 & 0,0 \\
ELISA & 200 & 100,0 & 0 & 0,0 & 0 & 0,0 \\
CL-ELISA & 0 & 0,0 & 7 & 3,5 & 193 & 96,5 \\
\hline
\end{tabular}

HI: hemaglutinação indireta; IFI: imunofluorescência indireta; ELISA; CL-ELISA: quimioluminescente-ELISA.

\section{DISCUSSÃo}

A técnica CL-ELISA é processada em tempo global similar ao de outros testes de ELISA convencionais. A manipulação de reagentes, assim como a execução do procedimento, também são de fácil aprendizado para profissional treinado. A propósito, porém, vale lembrar as dificuldades para manipulação e manutenção de formas infectantes do parasita, e obtenção do antígeno purificado, causando limitações à disponibilidade de kits comerciais relacionados com tal método.

Há necessidade de investimento inicial relacionado com 0 desenvolvimento da técnica, tanto para obtenção dos parasitas, extração e purificação antigênica, como para leitura da placa em 
quimioluminômetro, que cremos ser justificado pelos resultados obtidos.

Nossa averiguação, com caráter eminentemente prático, demonstrou a propósito de CL-ELISA indubitável ausência de valores de leitura presentes dentro da chamada zona cinza ou próximos a ela. Vale lembrar que neste contexto falta a existência de reação qualificada como gold standart, apta a permitir interpretações com resultado seguro.

Para avançar na resolução da incômoda ocorrência de resultados discordantes impõe-se programar avaliações com soros categoricamente de pessoas infectadas ou não através de documentação parasitológica.

Empregamos amostras de um contingente problemático, o do grupo de resultados discortantes, por dedução dos informes decorrentes HI, IFI e ELISA convencionais, pela divergência entre negatividade e positividades. Contudo, sem contarmos com teste gold standart e comprovação parasitológica da presença ou não de doença de Chagas merece cuidado eventual aceitação cabal do que foi verificado, no sentido de validar negativos e positivos. Nossa intenção básica consistiu em aduzir colaboração ao conhecimento do assunto, levando em consideração os altos índices de sensibilidade e especificidade da CL-ELISA, conforme constatações anteriores.

Nossa avaliação pautou-se sobretudo na intenção de verificar como o teste de CL-ELISA, utilizando um antígeno purificados de formas tripomastigotas (Muc-TCT), iria se comportar-se ante outros três procedimentos, em um grupo ambíguo de amostras com resultados discordantes. Não encontramos nenhum valor de leitura próximo ao limiar de reatividade, na casuística por nós utilizada.

Por enquanto, evidentemente, não é suficiente recorrer a um único tipo de prova para o diagnóstico laboratorial da doença de Chagas, mas a utilização do CL-ELISA (Muc-TCT) é por nós recomendada, incorporando-o a outros testes rotineiramente usados, que prestam apoio quando há intenção de diagnosticar a doença de Chagas.

\section{REFERÊNCIAS}

1. Almeida IC, Covas DT, Soussumi LM, Travassos LR. A highly sensitive and specific chemiliminescent enzyme-linked immunosobent assay for diagnosis of active Trypanosoma cruzi infection. Transfusion 37: 850-857, 1997.
2. Almeida IC, Rodrigues EG, Travassos LR. Chemiluminescent immunoassays: discrimination between the reactivities of natural and human patient antibodies with antigens from eukaryotic pathogens, Trypanosoma cruzi and Paracoccidioides brasiliensis. Journal of Clinical Laboratory Analysis 8: 424431, 1994.

3. Amato Neto V, De Marchi CR, Ferreira CS, Ferreira AW. Observações sobre o TESA blot no diagnóstico sorológico da doença de Chagas. Revista da Sociedade Brasileira de Medicina Tropical 38: 534-535, 2005.

4. Camargo ME. Introdução às técnicas de imunofluorescência. Revista Brasileira de Patologia Clínica 10: 57-71, 87-107, 143-171, 1974.

5. Camargo ME, Batista SM, Hoshino-Shimizu S. Avaliação de reagente liofilizado de hemaglutinação para diagnóstico da tripanossomíase americana. Estudo em 1.123 soros de doadores de sangue. Revista do Instituto de Medicina Tropical de São Paulo 17: 350-354, 1975.

6. Casadei CRDM, Braz LMA, Amato Neto V. Avaliação de prova sorológica, que utiliza peptídeos sintéticos, para o diagnóstico da doença de Chagas. Revista Brasileira de Clínica \& Terapêutica 26: 45-47, 2000.

7. De Marchi CR. Avaliação da resposta imune humoral contra mucinas purificadas e recombinantes de Trypanosoma cruzi. (resumo de tese) Revista do Instituto de Medicina Tropical de São Paulo 45: 258, 2003.

8. De Marchi CR, Amato Neto V. Diagnóstico sorológico da doença de Chagas: avaliação de modificação de prova que utiliza peptídeos sintéticos. Revista Brasileira de Clínica \& Terapêutica 28: 178-180, 2002.

9. De Marchi CR, Amato Neto V. Observações sobre o diagnóstico sorológico da doença de Chagas por Immunoblot. Laes \& Haes 23: 196-202, 2002.

10. De Marchi CR, Amato Neto V, Santos AG. Avaliação rotineira de prova de execução rápida (ELISA - ImunoComb II Chagas Ab) para diagnóstico sorológico da doença de Chagas. Revista da Sociedade Brasileira de Clínica Médica 3: 134-136, 2005.

11. Hoshino-Shimizu S, Camargo ME, Shimizu T, Nagasse TK. A study on the reproducibility os a stable, liophilized reagent for the Chagas' disease Hemagglutination test: proposals for quality control analysis. Revista do Instituto de Medicina Tropical de São Paulo 24: 63-68, 1982.

12. Sáez-Alquézar A, Luquetti A0, Borges-Pereira J, Moreira EL, Gadelha MFS, Garcia-Zapata MT, Arruda AHS. Estudo multicêntrico: avaliação do desempenho de conjuntos diagnósticos de hemaglutinação indireta, disponíveis no Brasil, para o diagnóstico sorológico da infecção pelo Trypanosoma cruzi. Revista de Patologia Clínica Tropical 26: 343-374, 1997.

13. Umezawa ES, Nascimento MS, Kesper N Jr, Coura JR, Borges-Pereira J, Junqueira AC, Camargo ME. Immunoblot assay using excreted-secreted antigens of Trypanosoma cruzi in serodiagnosis of congenital, acute, and chronic Chagas' disease. Journal of Clinical Microbiology 34: 2143-2147, 1996.

14. Voller A, Drapper C, Bidwell DE et al. Microplate enzyme-linked immunosorbent assay for Chagas' disease. Lancet 1: 426-428, 1975. 